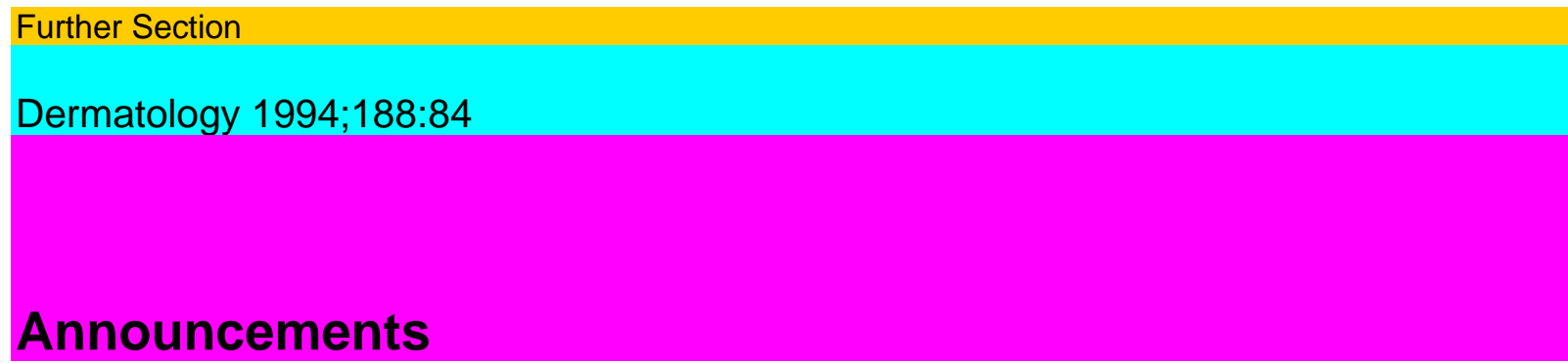

\title{
Dual Publication
}

The letter 'BCG-vaccine-induced lupus vulgaris and urticarial vasculitis' by L. Misery and P. Combemale [Dermatology 1993;186: 274] has previously been published in French as a case report entitled 'Urticaire systémique révélatrice d'un lupus vulgaire post-vaccina $[$ [Ann Dermatol Vénéréol 1993;120:233-235].

The authors have been asked for an explanatory letter according to the recommendations published in this journal [1991;182: 250-251]. The editors acknowledged the author's letter and decided to publish the present statement simultaneously in both journals.

The Editor

5th International Symposium on Atopic Dermatitis

The 5th International Symposium on Atopic Dermatitis will be held at the Rica Victoria Hotel, Lillehammer, Norway, May 22-25, 1994.

The scientific program will include different aspects of atopic dermatitis.

For information contact

Prof. Georg Rajka

Department of Dermatology

Rikshospitalet

N-0027 Oslo 1 (Norway)

Swiss Society of Dermatology and Venereolog $\gamma$

Dermatopathology Course in Cutaneous

Neoplasms

Graz, April 29 to May 1, 1994

Faculty: A.B. Ackerman (New York, Philadelphia); R.L. Barn-hill (Boston); D. Santa Cruz (St. Louis); H. Kerl (Graz)

Features will include:

A self-assessment workshop

Pitfalls in histopathologic diagnosis of malignant melanoma

Cutaneous adnexal tumors

For further information, please contact H.P. Soyer, MD Department of Dermatology University of Graz Auenbruggerplatz 8 A-8036 Graz (Austria) Phone (316) 385/2538 Fax (316) 385/3424 Course in postgraduate and continued education

'Methods of Physical Treatment in Dermatology' Zurich, September 26 and 27, 1994

Annual Meeting of the Swiss Society of Dermatology and Venereology on September 22-24, 1994, in Zurich

Meeting of the 'Workgroup of Dermatological Oncology' on September 24 and 25, 1994, in

Zurich

84

Announcements 